Article

\title{
Increased Adiposity Enhances the Accumulation of MDSCs in the Tumor Microenvironment and Adipose Tissue of Pancreatic Tumor-Bearing Mice and in Immune Organs of Tumor-Free Hosts
}

\author{
William J. Turbitt ${ }^{1,+} \mathbb{C}$, Shawntawnee D. Collins ${ }^{1,+}{ }^{\oplus}$, Huicui Meng ${ }^{1}$ and Connie J. Rogers ${ }^{1,2, *}$ \\ 1 Department of Nutritional Sciences, The Pennsylvania State University, University Park, PA 16802, USA; \\ billturbitt@gmail.com (W.J.T.); collinss217@gmail.com (S.D.C.); menghc@mail.sysu.edu.cn (H.M.) \\ 2 Penn State Cancer Institute, The Pennsylvania State University, Hershey, PA 16802, USA \\ * Correspondence: cjr102@psu.edu; Tel.: +1-814-867-3716; Fax: +1-814-863-6103 \\ + Authors contributed equally to manuscript.
}

Received: 7 October 2019; Accepted: 26 November 2019; Published: 10 December 2019

\begin{abstract}
Obesity is associated with increased risk and reduced survival for many types of cancer. Increasing adiposity may affect the balance between immunosuppressive and antitumor mechanisms critical for dictating cancer progression or remission. The goal of the current study was to determine if increased adiposity altered tumor growth, survival, and myeloid-derived suppressor cell (MDSC) accumulation in a subcutaneous murine model of pancreatic cancer. C57BL/6 mice were placed on a $30 \% \mathrm{kcal}$ calorie-restricted diet, $10 \% \mathrm{kcal}$ from fat diet fed ad libitum, or $60 \% \mathrm{kcal}$ from fat diet fed ad libitum for 16 weeks to generate lean, overweight, and obese mice, respectively; followed by subcutaneous injection with $1 \times 10^{6}$ Panc. 02 cells. We observed a significant linear relationship between increased adiposity and increased tumor growth and mortality; increased accumulation of Gr- $1^{+} \mathrm{CD} 11 \mathrm{~b}^{+}$MDSCs; and reduced CD8 T cell:MDSC ratio in multiple tissues, including tumor. Increased adiposity also increased the accumulation of MDSCs in the spleen and lymph node of tumor-free mice. These data suggest adiposity induces MDSC accumulation, which may contribute to an immunosuppressive environment promoting tumor growth. Overall, our findings provide a rationale to prevent or reverse increased body weight as a strategy to reduce the accumulation of immunosuppressive cell types.
\end{abstract}

Keywords: diet-induced obesity; calorie restriction; immunosuppression; survival; adipose tissue

\section{Introduction}

Cancer is a leading cause of death worldwide [1]. Obesity increases the risk of cancer at 13 sites, including breast, colon, and pancreas, among others [2,3]. Obesity is also associated with accelerated tumor progression, poorer response to treatment, and increased cancer-related mortality in multiple cancer types including pancreatic and breast cancer [4-6]. In addition to the well-established relationship between obesity in adulthood and poorer cancer outcomes, being overweight or obese during early life may also increase subsequent mortality risk for certain cancer types, including pancreatic cancer [7]. Emerging evidence suggests that survivors of childhood cancer experience significant weight gain early during the treatment window that is maintained after treatment concludes [8-10]. Survivors of childhood cancer also have a six-fold higher risk of developing second malignant neoplasms [11,12], and obesity during childhood cancer treatment contributes to this risk [13]. Thus, gaining a better understanding of the mechanisms linking obesity and cancer may lead to novel strategies to intervene and improve clinical outcomes in numerous cancer types. 
Several possible mechanisms, including immune modulation, may underlie the relationship between having obesity early in life and/or throughout adulthood on cancer risk, progression, and mortality. Obesity can promote tumor growth by modulating the balance between protective antitumor mechanisms and tumor-promoting/immunosuppressive factors [14-16]. Obesity impairs the function of cytotoxic $\mathrm{CD}^{+} \mathrm{T}$ cells and natural killer (NK) cells, two cell types with potent antitumor effector functions $[17,18]$. Obesity can also increase the immunosuppressive environment associated with tumor progression further blunting antitumor immune mechanisms. In particular, obesity-induced changes in inflammatory mediators may contribute to the expansion, accumulation, and activation of myeloid-derived suppressor cells (MDSCs) [19]. MDSCs are a diverse population of immature myeloid-lineage cells that accumulate in cancer, autoimmunity, and some chronic inflammatory conditions [20-22]. MDSCs can suppress cells of both the innate and adaptive immune system, including NK cells, macrophages, dendritic cells (DCs), and, in particular, T cells, via multiple mechanisms [23]. The accumulation of MDSCs correlates significantly with cancer stage and severity, and often coincides with a concurrent reduction in $\mathrm{CD} 8^{+} \mathrm{T}$ cells [24-26]. The mechanisms by which the expansion of adipose tissue contributes to the accumulation and function of MDSCs in tumor-free and tumor-bearing hosts remains unknown.

Pancreatic adenocarcinoma (PDAC) is an aggressive tumor type, with an overall five-year survival rate of $7 \%$ [27]. The infiltration of effector $\mathrm{CD} 8^{+} \mathrm{T}$ cells into the tumor confers a survival benefit and is predictive of a beneficial response to therapy; however, $\mathrm{CD}^{+} \mathrm{T}$ cells are found infrequently in the tumor microenvironment (TME) of pancreatic cancer patients [28-30]. In contrast, myeloid cells are highly prevalent in the TME, play a significant role in immune suppression, and are correlated with poor responses to therapy $[31,32]$. Obesity promotes an increase in circulating inflammatory cytokines and alters the infiltration of immune cells in PDAC, which is associated with increased tumor growth and metastasis [33,34]. However, additional studies are needed to determine if increasing adiposity changes the accumulation and function of immune suppressive myeloid cells.

Evaluating the role of obesity on the emergence of MDSCs in a murine model of pancreatic cancer may provide critical insight into the link between obesity, immune suppression, and poor clinical outcomes. Therefore, the goal of the current study was to determine if increased adiposity altered tumor growth, survival, and MDSC accumulation and function in a subcutaneous murine model of pancreatic cancer. This model was chosen because obesity exacerbates tumor growth [33,35], and we [36], and others [37], have demonstrated a role for the immune system in controlling Panc.02 tumor growth. An additional goal of this study was to determine if obesity alone (in the absence of tumor) enhanced the accumulation of MDSCs in relevant lymphoid organs.

\section{Materials and Methods}

\subsection{Tumor Cell Line and Cell Culture}

The murine ductal adenocarcinoma cell line Panc.02 was kindly provided by Dr. Jeffrey Schlom (National Cancer Institute, National Institute of Health). Panc.02 cells were cultured in McCoy's 5A without G418 (ThermoFisher Scientific; Waltham, MA, USA), and supplemented with 10\% FBS (Gemini BioProducts; Sacramento, CA, USA), $0.1 \mathrm{mM}$ nonessential amino acids (Mediatech; Manassas, VA, USA), $1 \mathrm{mM}$ sodium pyruvate (Mediatech), $2 \mathrm{mM}$ glutamine (Mediatech), $10 \mathrm{mM}$ HEPES (Mediatech), $100 \mathrm{U} / \mathrm{mL}$ penicillin streptomycin (Mediatech). Panc.02 tumor cells were maintained at $37^{\circ} \mathrm{C}$ and $5 \% \mathrm{CO}_{2}$ and passaged every 3-4 days using trypsin/EDTA (Mediatech).

\subsection{Animal Model}

Female 6-week-old C57BL/6 and BALB/c mice were obtained from Jackson Laboratory (Bar Harbor, MA, USA). All mice were housed at the Pennsylvania State University and maintained on a 12-h light/dark cycle with access to food and water. One cohort of mice $(n=90)$ was fed a semipurified control diet (D12450B, Research Diets, Inc., New Brunswick, NJ, USA) and were used to characterize 
the growth rate of Panc.02 tumors, evaluate the time course of $\mathrm{Gr} 1{ }^{+} \mathrm{CD} 11 \mathrm{~b}^{+} \mathrm{MDSC}$ accumulation, and assess the function of MDSCs in this model. A second cohort of mice $(n=130)$ were randomized to receive one of the following diets (all purchased from Research Diets, Inc.) for 16 weeks: (i) a control diet containing 10\% kcal from fat (D12450B; consumed ad libitum); (ii) a calorie-restricted (CR) diet (D03020702), a modified AIN-76A semipurified diet fed in daily aliquots to provide $30 \%$ less total energy and $100 \%$ of all vitamins, minerals, fatty acids, and amino acids relative to the control group; or (iii) diet-induced obesity (DIO) diet (D12492; consumed ad libitum), a modified (60 kcal\% fat) AIN-76A semipurified diet providing approximately $30 \%$ more total energy with $100 \%$ of vitamins, minerals, and amino acids, relative to the control diet. Diet formulations are shown in Supplementary Table S1. A subset of mice on each diet ( $n=12-14$ per group) were removed from the study prior to tumor injection to evaluate body composition, metabolic markers and immune cell distribution. All remaining mice continued on their respective diets following tumor implantation. Food intake and body weight were monitored as previously reported [38], and mice were observed daily for signs of ill health. Animal care was provided in accordance with the procedures outlined in the "Guide for the Care and Use of Laboratory Animals." The Institutional Animal Care and Use Committee of the Pennsylvania State University approved all animal experiments (IACUC protocol number 42335).

\subsection{Tumor Protocol}

Panc. 02 cells $\left(1 \times 10^{6}\right)$ were suspended in PBS and injected s.c. into the lumbar region of mice. Tumor growth was monitored three times per week with a digital caliper from day 13 post-tumor implantation until 60 days post-tumor implantation or when mice met criteria for removal of study (i.e., tumor volume exceeded $1.5 \mathrm{~cm}^{3}$ or animals were moribund). Tumor volume was calculated by multiplying the short side $\times$ short side $\times$ long side $/ 2 \times 0.001$ to get tumor volume in $\mathrm{cm}^{3}$.

\subsection{Immune Cell Depletion}

C57BL/6 mice ( $n=10-11 /$ group) were implanted s.c. with $1 \times 10^{6}$ Panc. 02 cells. Mice were injected i.p. with saline, $100 \mathrm{mg} /$ injection isotype control (clone LTF-2; BioXCell; West Lebanon, NH, USA), or $100 \mathrm{mg} /$ injection anti-Gr-1 (clone RB6-8C5; BioXCell) antibody every three days beginning at day 16 post-tumor implantation. Mice were sacrificed at day 40 post-tumor implantation.

\subsection{Body Composition Analysis}

Mouse carcasses were scanned using a GE Lunar PIXImus Dual-Energy X-ray Absorptiometer (DEXA) to assess lean mass, fat mass, and percent body fat, as previously described [39].

\subsection{Isolation of Spleen, Lymph Node and Tumor-Infiltrating Immune Cells}

Spleens, tumor-draining lymph nodes (TDLN), and tumors were harvested, and single-cell suspensions were prepared as previously described $[6,40]$. Cell counts and viability were determined via trypan blue exclusion (Corning; Tewksbury, MA, USA).

\subsection{Flow Cytometric Analyses}

Single cell suspensions of splenocytes, TDLN, and tumor-infiltrating immune cells were washed twice in PBS containing $0.01 \%$ bovine serum albumin at $4{ }^{\circ} \mathrm{C}$. Cells were incubated with Fc block (Biolegend; San Diego, CA, USA) and stained with saturating concentrations of conjugated antibodies, listedin Supplemental Table S2, as previously described [6,40]. Lymphoid and myeloid cells were gated on forward vs. side scatter, and a total of 30,000 events were acquired. Flow cytometric analyses were performed on a Beckman Coulter FC500 flow cytometer (Beckman Coulter; Indianapolis, IN, USA). Flow cytometric analyses were plotted and analyzed using Flow Jo software (Tree Star; Ashland, OR, USA). 


\subsection{MDSC Isolation}

MDSC s were isolated from a single cell suspension of splenocytes as per the manufacturer's instructions (MSDC Isolation kit; Miltenyi Biotec; Gladbach, Germany). Post-isolation MDSC subsets (Gr- ${ }^{\mathrm{Hi}} \mathrm{Ly}_{6 \mathrm{G}}{ }^{+}$ cells and $\mathrm{Gr}-\mathrm{1}^{\mathrm{Lo}} \mathrm{Ly} 6 \mathrm{G}^{-}$cells) were counted and viability was determined via trypan blue exclusion.

\section{9. $T$ Cell and APC Isolation}

$\mathrm{T}$ cells were isolated via negative selection using the Dynabeads $₫$ Untouched ${ }^{\mathrm{TM}}$ Mouse $\mathrm{T}$ cells Kit (Life Technologies; Carlsbad, CA, USA). APCs were isolated using the Dynabeads®Mouse Pan T (Thy1.2) Kit (Life Technologies). After isolation, T cells and APCs were counted, and viability was determined via trypan blue exclusion.

\subsection{Mixed Lymphocyte Reaction}

Isolated splenic T cells $\left(1 \times 10^{5}\right)$ from BALB/c animals were cocultured with irradiated (2000 rads) APCs $\left(5 \times 10^{5}\right)$ isolated from Panc.02 tumor-bearing C57BL/6 mice on each of the diets ( $n=7-8 /$ group), and either granulocytic $\left(\mathrm{Gr}-1^{\text {high }} \mathrm{Ly} 6 \mathrm{G}^{+}\right)$or monocytic $\left(\mathrm{Gr}-1^{\mathrm{dim}} \mathrm{Ly} 6 \mathrm{G}^{-}\right)$MDSCs $\left(5 \times 10^{4}\right)$. Cells were incubated in flat-bottomed, 96-well plates and were pulsed with $1 \mu \mathrm{Ci}$ per well of tritiated thymidine at $96 \mathrm{~h}$. Proliferation was assessed by tritiated thymidine $\left(\mathrm{H}^{3}\right)$ incorporation at $120 \mathrm{~h}$ (Perkin Elmer; Waltham, MA, USA) on a microbeta plate reader (Perkin Elmer). Each assay was performed in triplicate.

\subsection{Gene Expression}

Gene expression of Gr1, Il6, Il10, Cd3, Arg1, and Tgfb was assessed in the adipose tissue of Panc.02-tumor-bearing mice on each of the diets ( $n=8$ /group). Total RNA was extracted and genomic DNA contamination was removed by using RNeasy Mini Kit (Qiagen; Valencia, CA). Total RNA was quantified by using a Nanodrop 2000 spectrophotometer (ThermoFisher Scientific), and reverse-transcribed to cDNA using the High Capacity cDNA Reverse Transcription kit (Life Technologies). Real-time qPCR was performed by using TaqMan real time PCR reagents and an Applied Biosystems StepOnePlus Real-Time PCR System (Life Technologies). Primer sequences were based on previously published studies. Real-time qPCR data were calculated using the standard curve method and normalized to 18s RNA. Relative quantification or fold change in gene expression was determined using the $2^{\Delta \Delta C t}$ method using data from lean mice as reference control [41].

\subsection{Systemic Plasma Cytokine and Metabolic Marker Analysis}

Fasting blood was collected at sacrifice, centrifuged, and plasma was stored at $-80{ }^{\circ} \mathrm{C}$. IL-6 and leptin from tumor-free (TF, $n=5-7 /$ group) and Panc.02 tumor-bearing mice ( $n=5-8 /$ group) on each of the diets were measured using a Milliplex MAP Multiplex Assay (EMD Millipore; Billerica, MA, USA) and quantified on a Bio-plex 200 system (Bio-Rad; Hercules, CA) using Luminex-200 software (Luminex; Austin, TX, USA), per the manufacturer's instructions. Each assay was performed in duplicate.

\subsection{Statistical Analysis}

All data were assessed for normality and equal variances, and either parametric or nonparametric analyses were used to detect differences between treatment groups. If data were skewed, transformation (log or square root) was done prior to statistical analysis. Differences in tumor weight, plasma mediators, and the distribution of cells in the spleen, TDLN, and tumor-infiltrating cells were assessed between groups via a one-way ANOVA or Kruskal-Wallis test, depending on normality and variance. A post-hoc test for trend was done to assess the linear relationship between increasing adiposity (i.e., lean, overweight, obese phenotype) and immune outcomes. Body weight, food intake, and primary tumor volume were examined using a two-way ANOVA, followed by Tukey's or Bonferroni correction for multiple comparisons where appropriate. For survival studies, mice were counted as death for time to event analysis (survival analysis). All data are presented as the mean plus or minus the standard error 
of the mean. All analyses were conducted using GraphPad Prism 5 software (GraphPad Software; La Jolla, CA, USA) and statistical significance was accepted at the $p<0.05$ level.

\section{Results}

\subsection{The Panc.02 Model Is Characterized by a Shift Toward Suppressive Myeloid-Lineage Cells}

Panc.02 tumor-bearing mice $(n=25)$ had palpable tumors by day 19 post-implantation, as seen in Figure 1A. By day 60 post-tumor implantation, the mean tumor volume in Panc.02 tumor-bearing mice was $0.90 \pm 0.28 \mathrm{~cm}^{3}$. Splenocytes were isolated from tumor-free (TF; $n=8 /$ group) and Panc.02 tumor-bearing animals at 30 ( $n=2 /$ group), 40 ( $n=7 /$ group), 50 ( $n=9$ /group), and 60 ( $n=5 /$ group) days post-tumor implantation to characterize the time course and magnitude of the tumor-associated increase in the Gr- $1^{+} \mathrm{CD} 11 \mathrm{~b}^{+}$MDSC population. Both the percent(black bars; $p=0.005$ ), and number (open bars; $p=0.003$ ), of splenic Gr- $1^{+} \mathrm{CD} 11 \mathrm{~b}^{+}$MDSC s were significantly increased at day 50 and 60 post-tumor implantation, as seen in Figure 1B.

To test the ability of MDSC subsets to inhibit T cell proliferation, $\mathrm{T}$ cells from BALB/c mice were cultured with APCs from Panc.02 tumor-bearing mice $(n=7)$ in a mixed lymphocyte reaction (MLR) with and without MDSC subsets from Panc.02 tumor bearing mice. Both MDSC subsets significantly suppressed the proliferative capacity of T cells, as seen in Figure $1 \mathrm{C}(p=0.014)$. Gr- ${ }^{\mathrm{Hi}} \mathrm{CD} 11 \mathrm{~b}^{+}$gMDSCs inhibited T cell proliferation by $38.9 \pm 10.0 \%(p=0.020)$ and $\mathrm{Gr}-1^{\mathrm{Lo}} \mathrm{CD} 11 \mathrm{~b}^{+} \mathrm{mMDSC}$ inhibited T cell proliferation by $33.8 \pm 11.7 \%$ ( $p=0.047)$. To determine the contribution of MDSC accumulation to Panc.02 tumor progression, we examined the effect of depletion of this myeloid population on tumor growth. Depletion of $\mathrm{Gr}-1^{+}$cells beginning at day 16 post-tumor implantation significantly reduced Panc.02 tumor growth compared to PBS and isotype control antibody-treated mice, as seen in Figure 1D $(p<0.001)$.

\subsection{Increased Adiposity Significantly Enhances Tumor Growth While Decreasing Survival in Panc.02 Tumor-Bearing Mice}

Anthropometric measurements in mice following consumption of a $30 \%$ calorie-restricted diet, a $10 \% \mathrm{kcal}$ from fat diet ad libitum, and 60\% kcal from fat diet ad libitum for 16 weeks are displayed in Table 1. Data are pooled from two independent experiments, $n=12-14$ /group. Body weight, lean mass, fat mass, and percent fat were significantly different among the dietary interventions groups (one-way ANOVA $p<0.001$ for all outcomes). Mice fed the $10 \% \mathrm{kcal}$ from fat diet or the $60 \% \mathrm{kcal}$ from fat diet had significantly higher body weights $(p<0.001)$, lean mass $(p<0.001)$, fat mass $(p<0.001)$, and percent body fat $(p<0.010)$ compared to the $30 \%$ CR diet. Furthermore, mice fed the $10 \% \mathrm{kcal}$ from fat diet and the $60 \% \mathrm{kcal}$ from fat diet differed in body weight $(p<0.001)$, fat mass $(p<0.001)$, and percent body fat $(p<0.001)$. Based on the body composition analyses, mice consuming the $30 \% \mathrm{CR}$ diet, the $10 \% \mathrm{kcal}$ from fat diet ad libitum, and the $60 \% \mathrm{kcal}$ from fat diet ad libitum had significantly different percent body fat; thus, were categorized phenotypically as lean, overweight, and obese, respectively. Increasing adiposity resulted in elevated insulin, leptin, and IL-6 in both tumor free and Panc.02 tumor-bearing animals, as seen in Supplemental Figure S1.

Table 1. Body composition measures (mean \pm SEM) of mice on the three dietary treatment regimens ( $n=12-14$ /group).

\begin{tabular}{ccccc}
\hline Treatment Group & Body Weight (g) & Lean Mass (g) & Fat Mass (g) & \% Fat \\
\hline 30\% CR (lean) & $18.9 \pm 0.2$ & $13.1 \pm 0.3$ & $3.9 \pm 0.2$ & $23.2 \pm 0.7$ \\
$10 \%$ kcal from fat (overweight) & $25.9 \pm 0.7^{\mathrm{a}}$ & $16.7 \pm 0.3^{\mathrm{a}}$ & $7.9 \pm 0.6^{\mathrm{a}}$ & $31.5 \pm 1.5^{\mathrm{a}}$ \\
$60 \%$ kcal from fat (obese) & $35.1 \pm 1.5^{\mathrm{a}, \mathrm{b}}$ & $16.4 \pm 0.5^{\mathrm{a}}$ & $18.2 \pm 1.0^{\mathrm{a}, \mathrm{b}}$ & $49.0 \pm 2.3^{\mathrm{a}, \mathrm{b}}$ \\
\hline
\end{tabular}

${ }^{\mathrm{a}}$ significantly different from $30 \%$ calorie-restricted (CR) fed mice (Bonferroni correction $p<0.010$ ); ${ }^{\mathrm{b}}$ significantly different from $10 \% \mathrm{kcal}$ fat fed mice (Bonferroni correction $p<0.001$ ). 
A

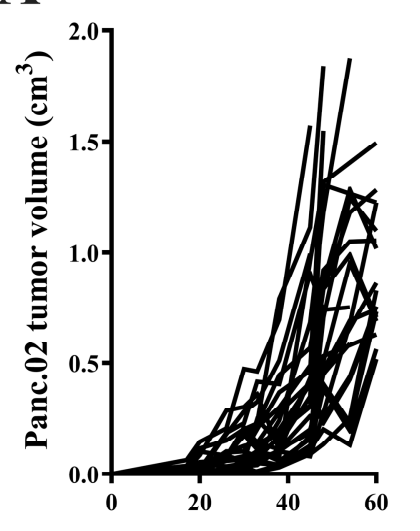

Days post-tumor implantation
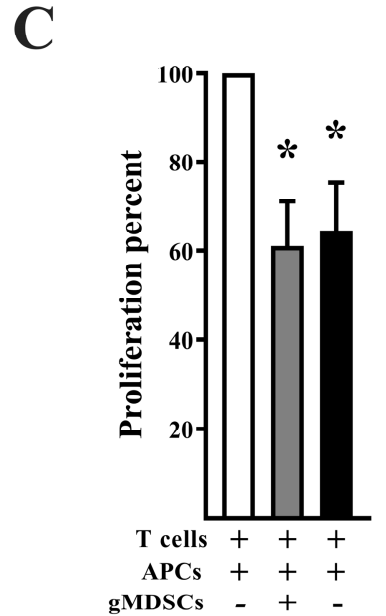

B

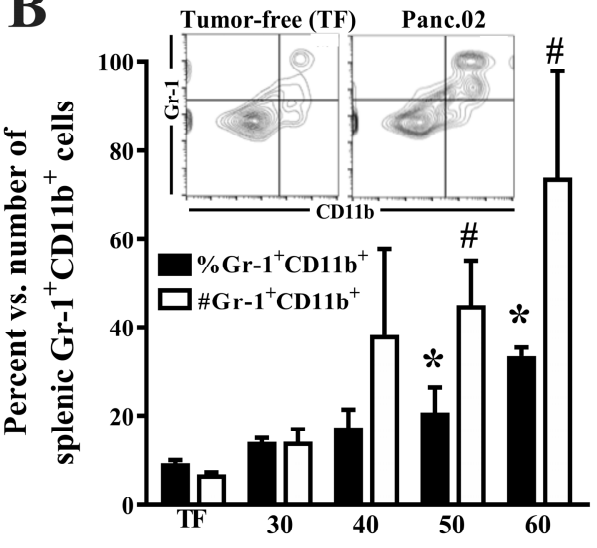

Days post-tumor implantation

D

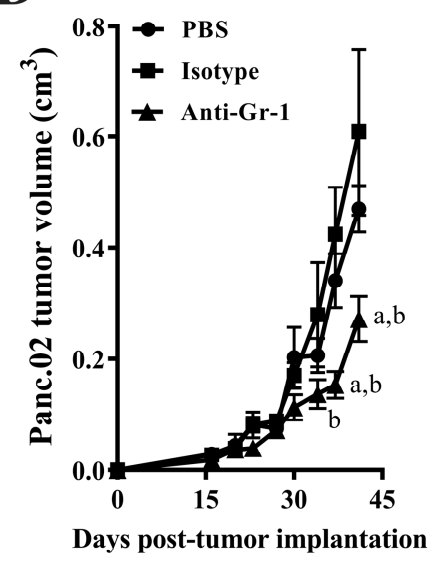

Figure 1. Tumor growth and the accumulation and function of suppressive myeloid cells in Panc.02 tumor-bearing mice. (A) Panc.02 tumor growth in C57BL/6 mice $(n=25)$. (B) The percent and number of splenic $\mathrm{Gr}-1^{+} \mathrm{CD} 11 \mathrm{~b}^{+}$cells in tumor-free (TF; $\left.n=8\right)$ and Panc.02 tumor-bearing mice at day 30 $(n=2), 40(n=7), 50(n=9)$, and $60(n=5)$ days post-tumor implantation was quantified by flow cytometry, as seen in the Figure 1B insert. Both the percent (black bars; KW $=14.90, p=0.005$ ) and number (open bars; $\mathrm{KW}=15.73, p=0.003$ ) of splenic $\mathrm{Gr}-1^{+} \mathrm{CD} 11 \mathrm{~b}^{+}$cells increased with tumor burden (asterisk or pound sign indicate significant difference from TF mice). (C) Irradiated (2000 Rads) antigen-presenting cells (APCs) and myeloid-derived suppressor cell (MDSC) subsets isolated from Panc.02 tumor-bearing mice (day 60 post-tumor implantation, $n=7$ ) were mixed with isolated splenic $\mathrm{T}$ cells from tumor free BALB/c mice in a mixed lymphocyte reaction. Cells were incubated for five days and proliferation was measured via thymidine incorporation. Percent of maximal proliferation is reported. T cell proliferation was inhibited by gMDSCs by $38.9 \pm 10.0 \%(p=0.020)$ and mMDSCs by $33.8 \pm 11.7 \%(p=0.047)$. Asterisk indicates a significant difference from wells containing T cells + APCs without either MDSC subset. (D) C57BL/6 mice ( $n=10-11 /$ group) were implanted s.c. with $1 \times 10^{6}$ Panc.02 cells and administered PBS, isotype control, or anti-Gr-1 antibody every three days beginning at day 16 post-tumor implantation. Depletion of $\mathrm{Gr}-1^{+}$cells reduced tumor volume compared to PBS and isotype control mice (two-way ANOVA, time $\times$ group, $\mathrm{F}_{(16,224)}=3.52, p<0.001$. Letters designate a significant difference from PBS (a) or isotype control antibody (b), Tukey's multiple comparison test, $p<0.05)$.

Overweight and obese mice had significantly increased tumor growth over time compared to lean mice, as seen in Figure $2 \mathrm{~A}(n=8 /$ group, $p=0.044)$. Increasing adiposity also significantly reduced survival in Panc.02 tumor-bearing mice, as seen in Figure 2B ( $n=12$ /group, Logrank test for trend, $p<0.010$ ). Median survival was 85, 63, and 51 days for lean, overweight, and obese mice, respectively. 


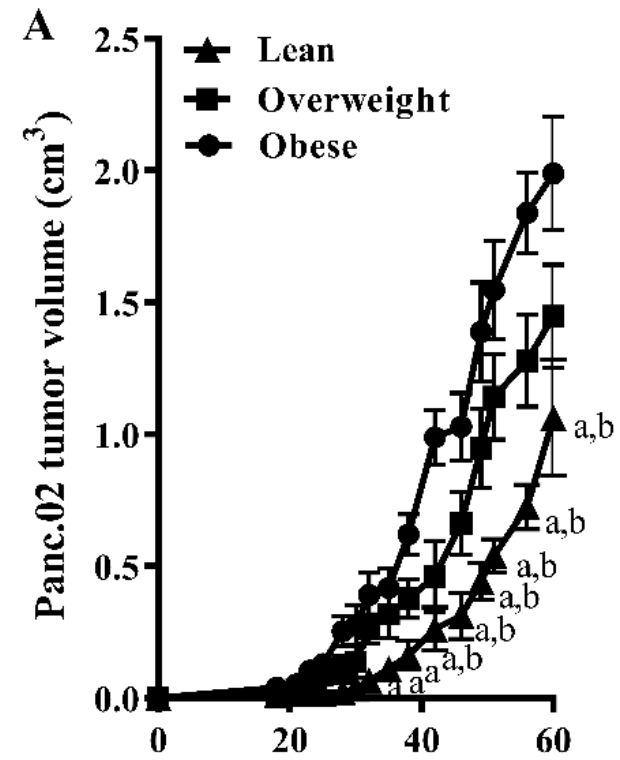

Days post-tumor implantation

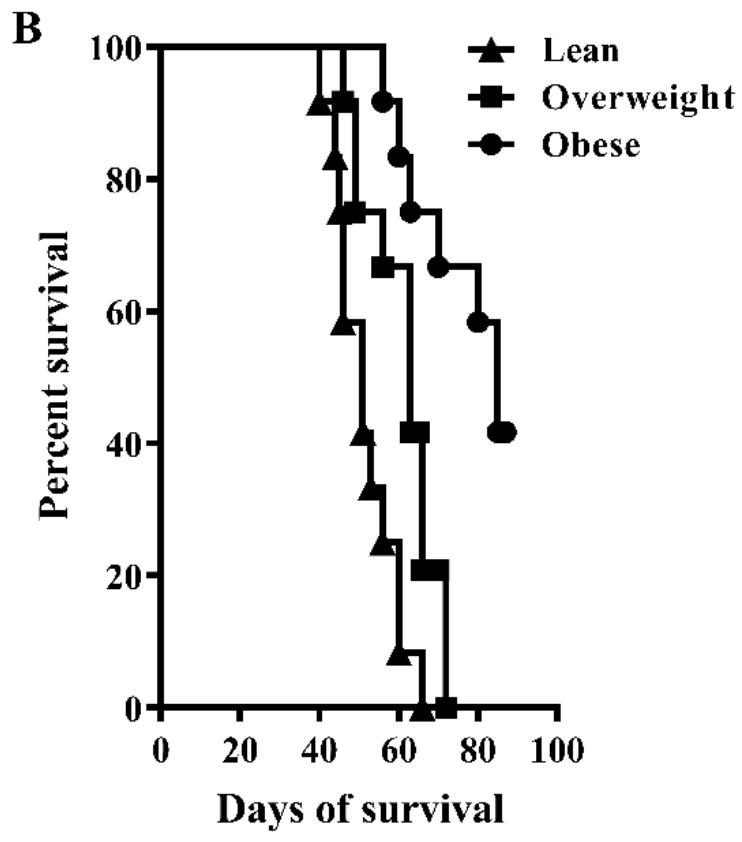

Figure 2. Increasing adiposity significantly enhances tumor growth while decreasing survival in Panc.02 tumor-bearing mice. (A) Tumor volume was significantly greater in overweight and obese compared to lean tumor-bearing mice (two-way repeated measures $\operatorname{ANOVA}, \mathrm{F}_{(50,525)}=1.392$, time $\times$ treatment group $p=0.044)$. Letters designate a significant difference from obese (a) or overweight (b) mice, Bonferroni multiple comparison test, $p<0.05$ ). (B) Increasing adiposity significantly reduced survival, as seen in Figure 2B ( $n=12$ /group, Logrank test for trend, $p<0.010)$.

3.3. Increased Adiposity Induces the Expansion of Immunosuppressive Cell Populations and Reduces the Splenic CD $8^{+}$T Cell to MDSC Ratio

A bivariate plot of splenic MDSC subsets using $\mathrm{Gr}-1^{\mathrm{Hi}} / \mathrm{Gr}-1^{\mathrm{Lo}}$ vs. CD11b expression, as seen in Figure 3A, is shown from a representative lean, overweight, and obese Panc.02 tumor-bearing mouse. The total number of splenic Gr- $1^{+} \mathrm{CD} 11 \mathrm{~b}^{+}$MDSCs was correlated with tumor volume at sacrifice, as seen in Figure 3B (Pearson's $\mathrm{r}=0.764, p<0.001$ ). The percentage of total splenic $\mathrm{CD}^{+} \mathrm{T}$ cells $(p=0.011)$ and splenic CD $4^{+} \mathrm{T}$ cells, as seen in Figure 3C.

Figure 3C $(p=0.048)$ was significantly reduced with increasing adiposity in a linear relationship (post-hoc test for trend, $p=0.003$ and $p=0.017$, respectively). The percent of splenic CD8 ${ }^{+} \mathrm{T}$ cells was reduced with increasing adiposity, although this did not reach statistical significance. Increased adiposity significantly increased the percentage of total splenic Gr-1 $1^{+} \mathrm{CD} 11 \mathrm{~b}^{+}$MDSCs $(p=0.009)$ and $\mathrm{Gr}-1^{\mathrm{Hi}} \mathrm{CD} 11 \mathrm{~b}^{+}$gMDSCs $(p=0.017)$, as seen in Figure 3D. No differences emerged between groups in the percentage of $\mathrm{Gr}-1^{\mathrm{Lo}} \mathrm{CD} 11 \mathrm{~b}^{+}$mMDSCs, as seen in Figure 3D, or in the splenic gMDSC:mMDSC ratio, as seen in Figure 3E. However, a significantly reduced $\mathrm{CD} 8^{+} \mathrm{T}$ cell:MDSC ratio $(p=0.046)$, CD8 T cell:gMDSC ratio $(p=0.049)$, and CD8:mMDSC ratio $(p=0.016)$ was observed with increasing adiposity, as seen in Figure 3F. Both granulocytic and monocytic MDSCs reduced T cell proliferation (one-way ANOVA; $\mathrm{F}_{(1,22)}=6.88 ; p=0.010$ ); however, no significant differences were observed in the suppressive capacity of MDSC subsets on a per cell basis among lean, overweight and obese mice, as seen in Figure 3G. No significant differences were observed in other splenic immune cell populations among lean, overweight, and obese mice, as seen in Supplemental Table S3. 

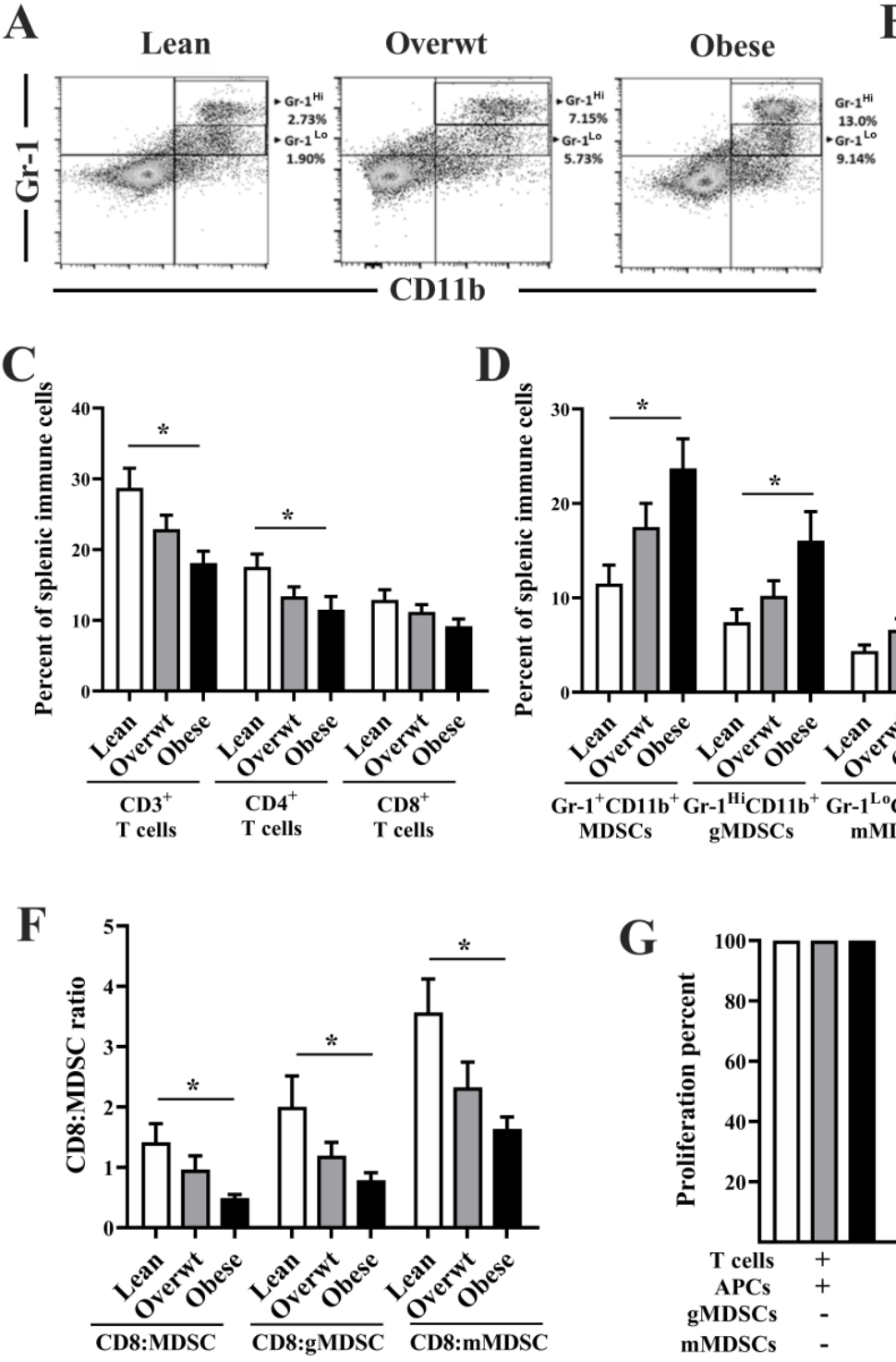

D

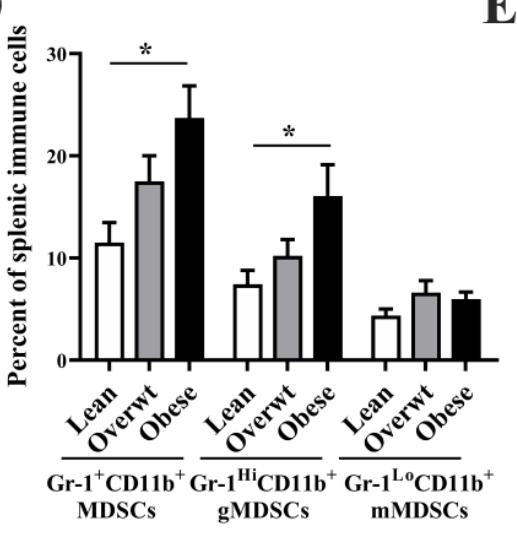

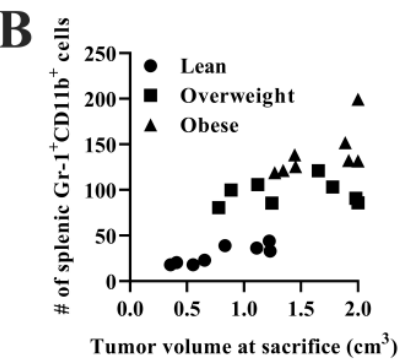

$\mathbf{E}$

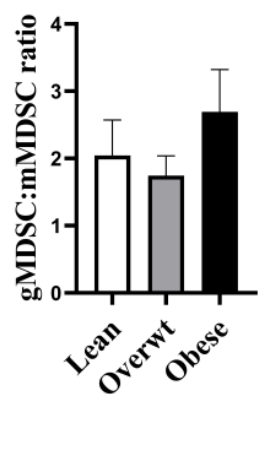

Figure 3. A significant linear relationship exists between increasing adiposity and the accumulation of splenic $\mathrm{Gr}-1^{+} \mathrm{CD} 11 \mathrm{~b}^{+}$cells and a reduction in the CD8 T cell to MDSC ratio in Panc.02 tumor-bearing animals. (A) Representative bivariate plot using Gr-1 ${ }^{\mathrm{Hi}} \mathrm{Gr}-1^{\mathrm{Lo}}$ vs. CD11b expression in the spleen of a lean, overweight, and obese Panc.02 tumor-bearing mouse 60 days post-tumor implantation. Arrows indicate different subpopulations of MDSCs subsets $\left(\mathrm{Gr}-1^{\mathrm{Hi}} \mathrm{CD} 11 b^{+}\right.$and $\left.\mathrm{Gr}-1^{\mathrm{Lo}} \mathrm{CD} 11 \mathrm{~b}^{+}\right)$in lean $(2.71 \%, 1.90 \%)$, overweight $(7.15 \%$ and $5.73 \%)$, and obese $(13.0 \%$ and $9.14 \%)$ Panc.02 tumor-bearing animals ( $n=7-8 /$ group). (B) End tumor volume was significantly correlated with the number of splenic Gr- $1^{+} \mathrm{CD} 11 b^{+}$cells at sacrifice (Pearson's $r=0.764, p<0.001$ ). (C) Increasing adiposity significantly reduced percentage of splenic $\mathrm{CD}^{+} \mathrm{T}$ cells (one-way ANOVA, $\mathrm{F}_{(2,34)}=5.14, p=0.011$ ) and $\mathrm{CD}^{+}$ T cells (one-way ANOVA; $\mathrm{F}_{(2,33)}=3.34, p=0.048$ ) and increased the percentage of $(\mathbf{D})$ total splenic Gr- $1^{+} \mathrm{CD} 11 b^{+}$MDSCs (one-way ANOVA, $\mathrm{F}_{(2,34)}=5.47, p=0.009$ ) and Gr- $1^{\mathrm{Hi}} \mathrm{CD} 11 \mathrm{~b}^{+}$gMDSCs (one-way ANOVA, $\mathrm{F}_{(2,34)}=4.52, p=0.017$ ). (E) No significant difference was observed in splenic gMDSC:mMDSC ratio. Increasing adiposity resulted in a significantly lower $(\mathbf{F})$ CD8 T cell:MDSC ratio (one-way ANOVA, $\left.\mathrm{F}_{(2,33)}=3.37, p=0.046\right)$, CD8 T cell:gMDSC ratio (one-way ANOVA; $\mathrm{F}_{(2,33)}=3.34, p=0.049$ ), and CD8 T cell:mMDSC ratio (one-way ANOVA, $\mathrm{F}_{(2,33)}=4.67, p=0.016$ ). Asterisks indicate a significant post-hoc test for trend based on body composition. $(\mathrm{G})$ Both granulocytic and monocytic MDSCs reduced $\mathrm{T}$ cell proliferation (one-way ANOVA, $\mathrm{F}_{(1,22)}=6.88 ; p=0.010$ ); however, no significant differences were observed in the suppressive capacity of MDSC subsets on a per cell basis among lean, overweight, and obese mice. 
3.4. Increased Adiposity Induces the Expansion of Immunosuppressive Cell Populations and Reduces the CD8 $8^{+}$ $T$ Cell to MDSC Ratio in the Tumor-Draining Lymph Node and Tumor Microenvironment

The percentage of TDLN CD3 ${ }^{+}(n=8$ /group; $p<0.001), \mathrm{CD}^{+} 4 \mathrm{~A}(p<0.001)$, and CD8 ${ }^{+}$ $(p<0.001)$ T cells was significantly reduced with increasing adiposity, as seen in Figure $4 \mathrm{~A}$. Increased adiposity significantly increased Gr- $1^{+} \mathrm{CD} 11 \mathrm{~b}^{+}$MDSCs $(p<0.001), \mathrm{Gr}-1^{\mathrm{Hi}} \mathrm{CD} 11 \mathrm{~b}^{+}$gMDSCs $(p<0.001)$, and $\mathrm{Gr}-1^{\mathrm{Lo}} \mathrm{CD} 11 \mathrm{~b}^{+}$mMDSCs $(p<0.001)$ in the TDLN, as seen in Figure 4B. Increasing adiposity shifted the TDLN gMDSC:mMDSC ratio to favor the presence of mMDSCs, as seen in Figure $4 \mathrm{C}$ $(p<0.001)$. A reduction in the TDLN CD8 T cell:MDSC ratio $(p<0.001), \mathrm{CD} 8 \mathrm{~T}$ cell:gMDSC ratio $(p<0.001)$, and'CD8 T cell:mMDSC ratio $(p<0.001)$ was observed with increased adiposity, as seen in Figure 4D. No significant differences were observed in other TDLN immune cell populations among lean, overweight, and obese mice, as seen in Supplemental Table S4.

A

C
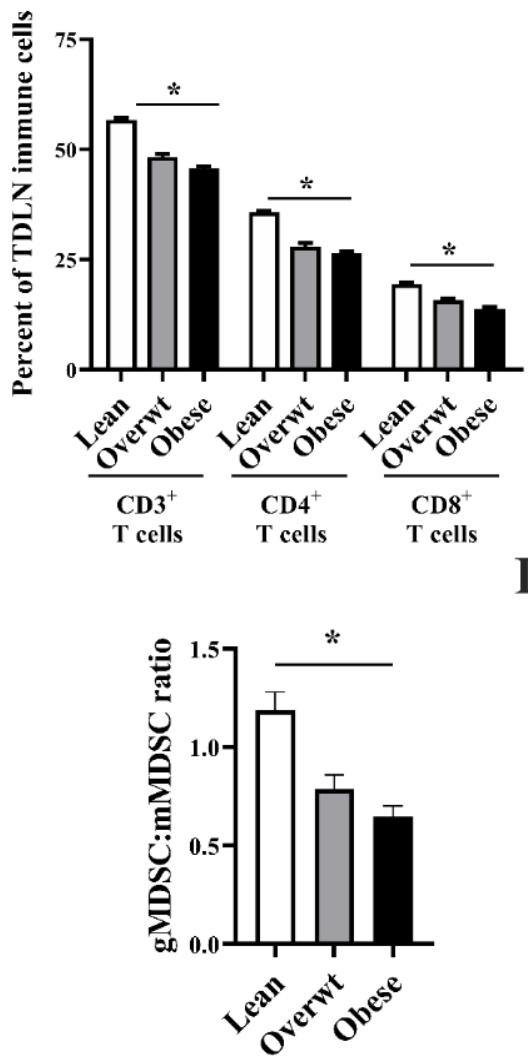

B

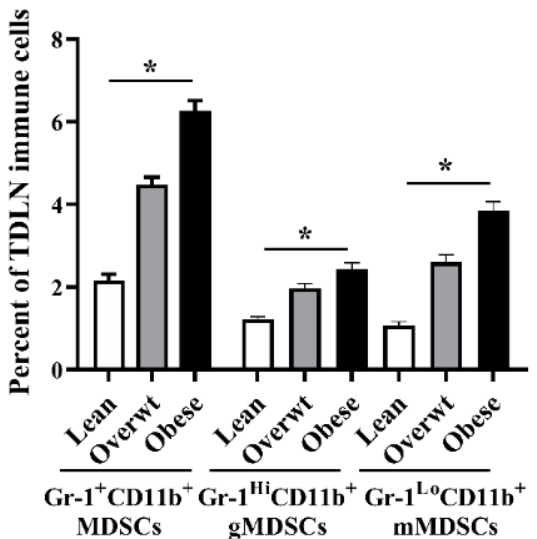

D

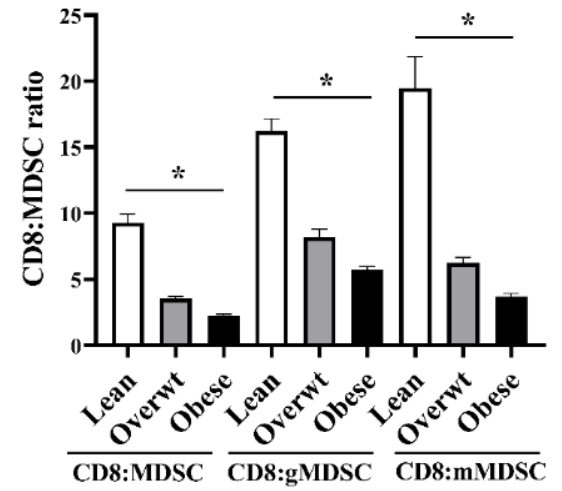

Figure 4. A significant linear relationship exists between increasing adiposity and the accumulation of TDLN Gr- $1^{+}$CD11 $b^{+}$cells and a reduction in the CD8 T cell to MDSC ratio in Panc.02 tumor-bearing animals. (A) Increased adiposity significantly reduced the percentage of $\mathrm{CD}^{+}$( $n=8 /$ group; one-way ANOVA; $\mathrm{F}_{(2,21)}=109.50, p<0.001$ ), $\mathrm{CD}^{+}$(one-way ANOVA; $\mathrm{F}_{(2,21)}=73.75, p<0.001$ ), , and CD8 ${ }^{+}$ (one-way ANOVA; $\mathrm{F}_{(2,21)}=43.72, p<0.001$ ) TDLN T cells. (B) Increased adiposity significantly increased Gr- $1^{+}$CD11b ${ }^{+}$MDSCs (one-way ANOVA; $\mathrm{F}_{(2,21)}=106.10, p<0.001$ ), Gr- $1^{\mathrm{Hi}} \mathrm{CD} 11 \mathrm{~b}^{+}$gMDSCs (one-way ANOVA; $\mathrm{F}_{(2,21)}=31.07, p<0.001$ ), and $\mathrm{Gr}-1^{\mathrm{Lo}} \mathrm{CD} 11 \mathrm{~b}^{+}$mMDSCs (one-way ANOVA, $\mathrm{F}_{(2,21)}$ $=69.45, p<0.001)$ in the TDLN. (C) Increasing adiposity shifted the TDLN gMDSC:mMDSC ratio to favor the presence of mMDSCs (one-way ANOVA, $\mathrm{F}_{(2,21)}=13.94, p<0.001$ ). (D) Increasing adiposity significantly lowered the TDLN CD8 T cell:MDSC ratio (one-way ANOVA, $\mathrm{F}_{(2,21)}=88.60, p<0.001$ ), CD8 T cell:gMDSC ratio (one-way ANOVA, $\mathrm{F}_{(2,21)}=119.70, p<0.001$ ), and CD8 T cell:mMDSC ratio (one-way ANOVA, $\mathrm{F}_{(2,21)}=36.35, p<0.001$ ). Asterisks indicate a significant post-hoc test for trend based on body composition $(p<0.001)$. 
The percentage of tumor-infiltrating $\mathrm{CD}^{+}(n=8$ /group; $p<0.001), \mathrm{CD}^{+}(p<0.001)$, and $\mathrm{CD}^{+}$ $(p<0.001) \mathrm{T}$ cells was significantly reduced with increasing adiposity, as seen in Figure 5A. Increasing adiposity resulted in a significant increase in tumor-infiltrating Gr- $1^{+} \mathrm{CD} 11 \mathrm{~b}^{+}$MDSCs $(p<0.001)$, Gr- $1{ }^{\mathrm{Hi}} \mathrm{CD} 11 \mathrm{~b}^{+}$gMDSCs 5B $(p=0.009)$ and Gr- ${ }^{\mathrm{Lo}} \mathrm{CD} 11 \mathrm{~b}^{+}$mMDSCs $(p<0.001)$, as seen in Figure 5B. Increased adiposity shifted the tumor-infiltrating gMDSC:mMDSC ratio to favor the presence of mMDSCs, as seen in Figure 4C $(p<0.001)$. A reduction in the tumor-infiltrating CD8 T cell:MDSC ratio $(p<0.001)$, CD8 T cell:gMDSC ratio $(p<0.001)$, and CD8 T cell:mMDSC ratio, as seen in Figure 4D $(p<0.001)$ was observed with increased adiposity.

A

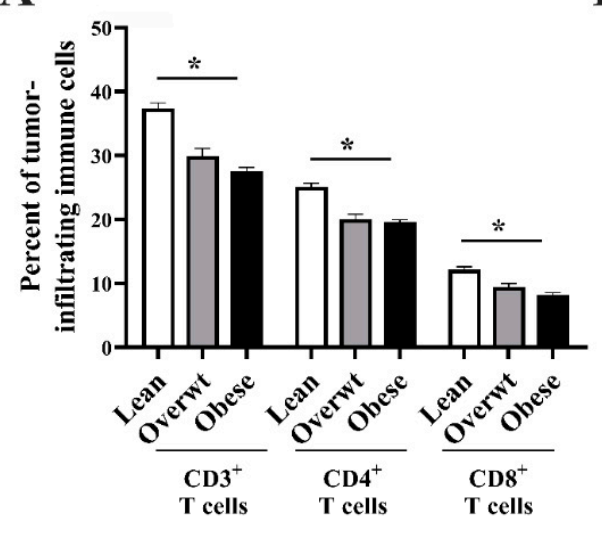

C

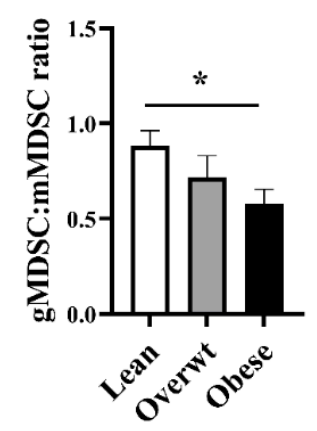

B

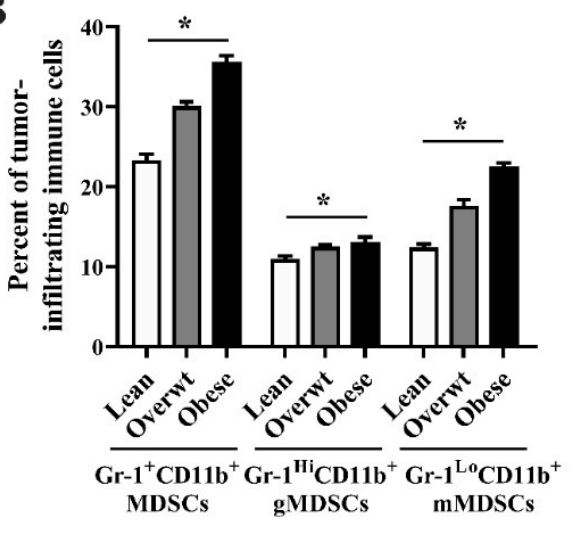

D

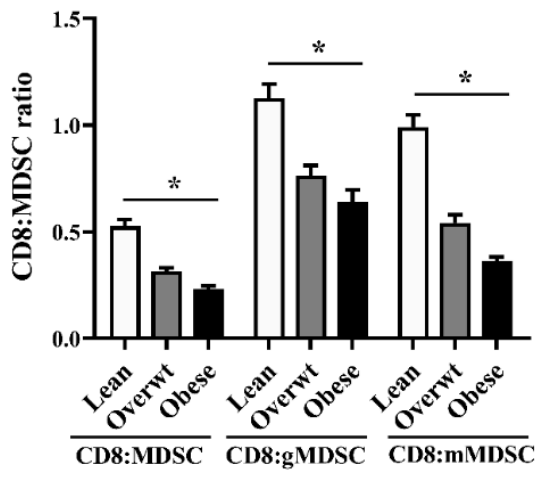

Figure 5. A significant linear relationship exists between increased adiposity and an increase in the accumulation of tumor infiltrating Gr- $1^{+} \mathrm{CD} 11 \mathrm{~b}^{+}$cells and a decrease in the CD8 $\mathrm{T}$ cell to MDSC ratio in Panc.02 tumor-bearing animals. (A) Increased adiposity significantly reduced the percentage of $\mathrm{CD}^{+}$ $\left(n=8 /\right.$ group; one-way ANOVA; $\mathrm{F}_{(2,21)}=30.91, p<0.001$ ), $\mathrm{CD}^{+}$(one-way ANOVA; $\mathrm{F}_{(2,21)}=27.76$, $p<0.001$ ), and CD8 ${ }^{+}$(one-way ANOVA; $\mathrm{F}_{(2,21)}=20.05, p<0.001$ ) $\mathrm{T}$ cells in the tumor. (B) Increased adiposity significantly increased Gr- $1^{+} \mathrm{CD} 11 \mathrm{~b}^{+}$MDSCs (one-way ANOVA, $\mathrm{F}_{(2,21)}=76.62, p<0.001$ ), Gr- $1^{\mathrm{Hi}} \mathrm{CD} 11 \mathrm{~b}^{+}$gMDSCs (one-way ANOVA, $\mathrm{F}_{(2,21)}=5.88, p=0.009$ ), and $\mathrm{Gr}-1^{\mathrm{Lo}} \mathrm{CD} 11 \mathrm{~b}^{+}$mMDSCs (one-way ANOVA, $\left.\mathrm{F}_{(2,21)}=88.25, p<0.001\right)$ in the tumor. (C) Increasing adiposity shifted the gMDSC:mMDSC ratio in the tumor to favor the presence of mMDSCs (on one-way ANOVA, $\mathrm{F}_{(2,21)}$ $=23.16, p<0.001)$. (D) Increasing adiposity significantly lowered the TDLN CD8 T cell:MDSC ratio (one-way ANOVA, $\left.\mathrm{F}_{(2,21)}=46.74, p<0.001\right)$, CD8 T cell:gMDSC ratio (one-way ANOVA, $\mathrm{F}_{(2,21)}=19.40$, $p<0.001$ ), and CD8 T cell:mMDSC ratio (one-way ANOVA, $\left.\mathrm{F}_{(2,21)}=64.24\right)$. Asterisks indicate a significant post-hoc test for trend based on body composition $(p<0.010)$.

3.5. Increased Adiposity Induces the Expansion of Immunosuppressive Cell Populations in Adipose Tissue of Panc.02 Tumor-Bearing Animals and Immune Compartments in Tumor-Free Mice

The abundance of Gr1, Il6, and Il10, which encode Gr-1, the myeloid differentiation marker found on granulocytes, macrophages, and MDSCs, and the cytokines IL-6 and IL-10, which can contribute to the recruitment of MDSCs [42], was elevated with increasing adiposity in the adipose tissue of 
Panc.02 tumor-bearing mice, as seen in Figure 6A. Furthermore, the abundance of Cd3, Arg1, and Tgfb, which encode the $\mathrm{T}$ cell co-receptor CD3, arginase-1, an enzyme found in immunosuppressive myeloid cells [43], and the immunoregulatory cytokine, transforming growth factor-beta (TGF- $\beta$ ) that can be released from MDSCs to inhibit $\mathrm{T}$ cell function [42], was elevated with increasing adiposity in the adipose tissue of Panc.02 tumor-bearing mice, as seen in Figure 6B. In tumor-free mice, increased adiposity significantly increased the percentage of inguinal lymph node MDSCs, as seen in Figure 6C $(p=0.002)$ and splenic $(p=0.001) \mathrm{Gr}-1^{+} \mathrm{CD} 11 \mathrm{~b}^{+}$MDSCs, as seen in Figure 6D.
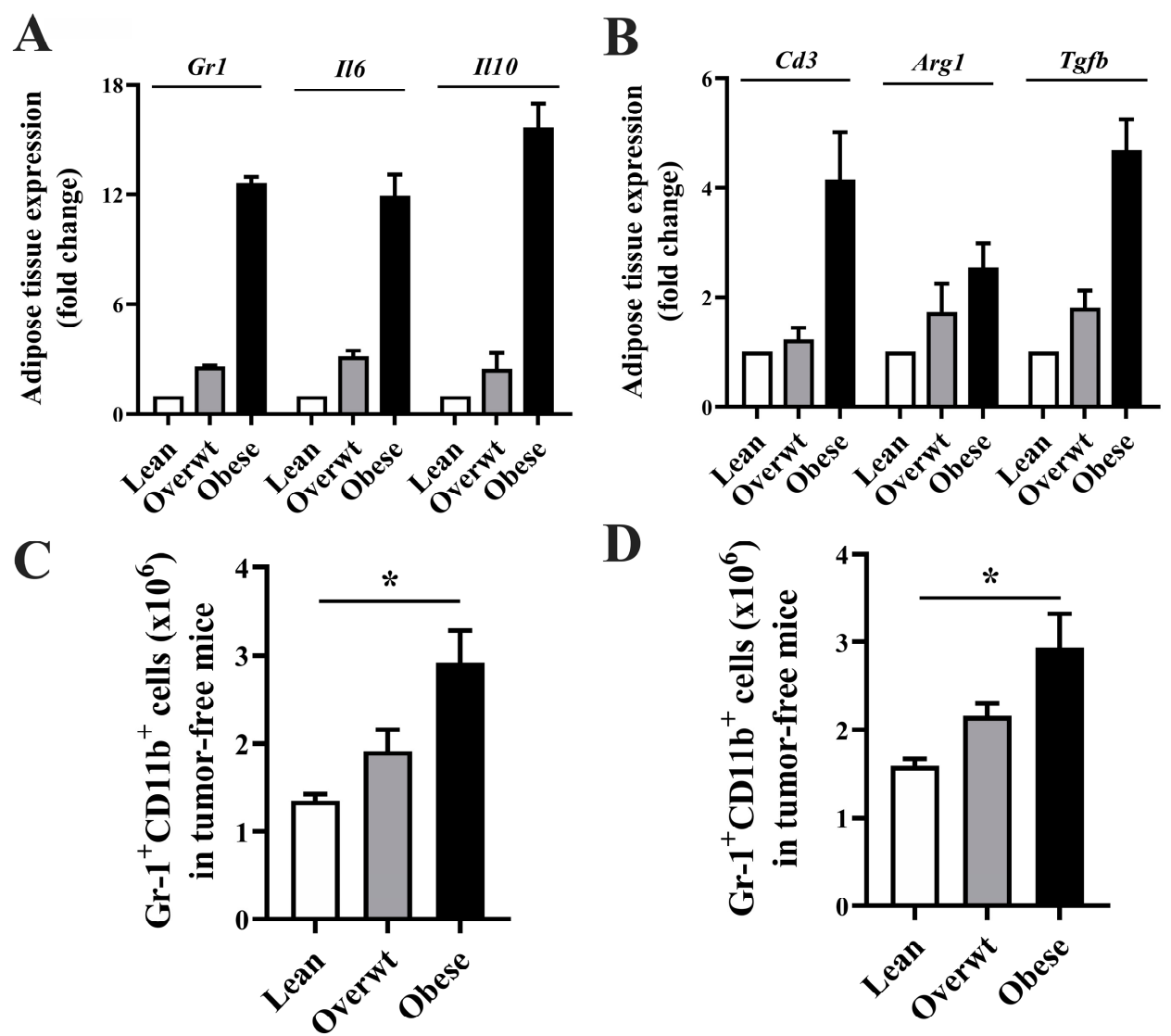

D

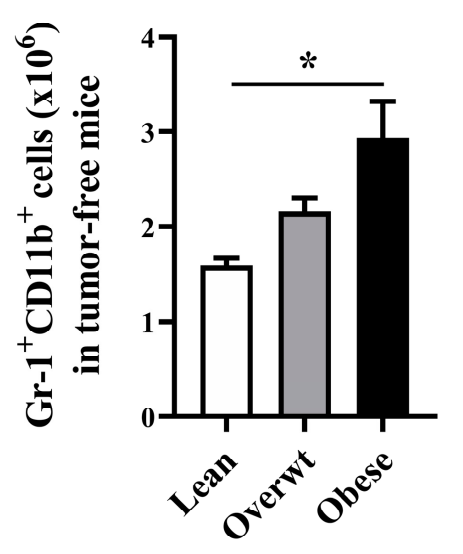

Figure 6. Increasing adiposity induces the upregulation of inflammatory and MDSC-associated markers in the adipose tissue of tumor-bearing mice and induces the expansion of immunosuppressive cell populations in immune compartments in tumor-free mice. The abundance of immune-related (A,B) genes within the adipose tissue microenvironment was increased in obese Panc.02 tumor-bearing animals ( $n=8$ /group). In tumor-free mice, increased adiposity significantly increased the percentage of (C) inguinal lymph node (one-way ANOVA, $\mathrm{F}_{(2,15)}=9.48, p=0.002$ ) and (D) splenic (one-way ANOVA, $\left.\mathrm{F}_{(2,15)}=8.190, p=0.001\right) \mathrm{Gr}-1^{+} \mathrm{CD} 11 \mathrm{~b}^{+}$MDSCs. Asterisks indicate a significant post-hoc test for trend based on body composition.

\section{Discussion}

We demonstrated that Panc.02 tumor-bearing mice accumulate immunosuppressive MDSCs in multiple sites, including spleen, tumor draining lymph node, tumor, and adipose tissue. Antibody depletion of Gr-1+ MDSCs significantly reduced Panc.02 tumor growth demonstrating a functional role for MDSCs in tumor progression. We demonstrated that as we increased adiposity across the continuum of lean, overweight, and obesity, we increased pancreatic tumor growth and decreased survival in a dose-dependent manner. We also observed a significant linear relationship between increasing adiposity and both the accumulation of $\mathrm{Gr}-1^{+} \mathrm{CD} 11 \mathrm{~b}^{+}$cells, and a reduction in the CD8 T cell to MDSC ratio in multiple lymphoid organs and within the TME in Panc.02 tumor-bearing animals. 
Furthermore, the increase in adiposity resulted in elevated inflammatory and immunosuppressive myeloid markers in the adipose tissue in Panc.02 tumor-bearing mice and increased the expansion of Gr- $1^{+} \mathrm{CD} 11 \mathrm{~b}^{+}$cells in secondary lymphoid organs in the absence of tumor. These data suggest that increasing adiposity may be creating an immunosuppressive environment in key tissues during and prior to tumor development.

Both clinical and preclinical models investigating the balance between tumor-promoting/immunosuppressive factors and protective antitumor mechanisms critical for influencing cancer progression often fail to assess the contributions of common modifying factors, such as age and increased adiposity. In $2016,39 \%$ of adults were overweight and $13 \%$ were obese worldwide [44,45] and obesity is a major risk factor for pancreatic cancer [2]; thus, it is imperative to understand both the direct and indirect effects of obesity on cancer progression [46]. Obesity is a pathological state associated with dysregulated inflammatory and metabolic mediators, including blood glucose, insulin, IGF-1, and leptin [47]. Leptin, an adipokine correlated with adipose tissue mass [48], is elevated in people with obesity and obese mice, an observation confirmed in the current study, and may play a cancer promoting role in obesity-related cancers [15]. Clinically, high prediagnostic levels of serum leptin are associated with an increase in the risk of pancreatic cancer (odds ratio $=2.55$ (95\% CI, 1.23-5.27) [49]. Both diet-induced obesity and models of genetic obesity show increases in serum leptin, concurrently with increased tumor growth and metastasis in murine models of pancreatic cancer [50-52]. Conversely, the progression from intraepithelial lesions to PDAC is delayed in mice administered a prolonged calorie restriction diet in both orthotopic and genetic models of pancreatic cancer [35]. Previous reports, and the current study, suggest that lean mice have slower tumor growth and better survival outcomes than obese mice; furthermore, in the current study, we demonstrate that there is a linear relationship between adiposity and these outcomes. These data in murine models of pancreatic cancer are consistent with the epidemiological data demonstrating a link between obesity and pancreatic risk and mortality $[53,54]$.

Our data demonstrate that increasing adiposity decreased the percentage of total $\mathrm{CD}^{+} \mathrm{T}^{-}$cells, $\mathrm{CD} 4^{+}$helper $\mathrm{T}$ cells, and $\mathrm{CD} 8^{+}$cytotoxic $\mathrm{T}$ cells in the spleen, tumor draining lymph node, and TME. Similar to previous reports detailing $\mathrm{T}$ cell impairments in response to obesity [55], these data demonstrate that obesity can alter the percentage of lymphoid cells across multiple tissue types. However, we also demonstrate that the observed effects on immune cell distribution are linearly related to the degree of adiposity, with overweight mice having an intermediate phenotype between lean and obese mice. In addition to obesity-induced impairments in antitumor immunity, increasing adiposity stimulates tumor-derived immunosuppressive factors to drive the expansion of suppressive myeloid lineage cells, including MDSCs. MDSCs are early myeloid-lineage cells and precursors of macrophages, dendritic cells, and granulocytes [56]. Murine MDSCs are comprised of two subsets, granulocytic $\left(\mathrm{Gr}-1^{\mathrm{Hi}} \mathrm{CD} 11 \mathrm{~b}^{+}\right)$MDSCs and a monocytic $\left(\mathrm{Gr}-1^{\mathrm{Lo}} \mathrm{CD} 11 \mathrm{~b}^{+}\right)$MDSCs, each contributing to disease progression by suppressing both innate and adaptive antitumor immune responses through multiple mechanisms [23,57]. Similar to previous preclinical subcutaneous pancreatic [58] and orthotopic renal [59] models, we demonstrate that with increasing adiposity, an expansion of total MDSCs, gMDSCs, and mMDSCs occurred in the spleen, tumor draining lymph node, and TME. We also noted a preferential expansion of mMDSCs within the TME in overweight and obese mice, suggesting that increased adiposity can alter MDSC subset distribution in a tissue specific manner. However, similar to previous reports [59], splenic MDSC subsets from all dietary groups were equally suppressive on a per cell basis. While equally suppressive, prevention of the accumulation of MDSCs by the maintenance of a lean phenotype may be physiologically important and suggestive of prolonged antitumor immunity.

Clinically, MDSCs accumulate in pancreatic cancer patients, and their accumulation correlates with disease progression $[60,61]$. The accumulation of MDSCs in cancer patients is also associated with a concurrent reduction in $\mathrm{CD} 8^{+} \mathrm{T}$ cells [62]. However, the impact of increased adiposity on the CD8 T cell to MDSC ratio in cancer patients remains unknown, but may be related to clinical outcomes in numerous cancer types. In the current study, increased adiposity induced an unfavorable shift in the 
$\mathrm{CD}^{+} \mathrm{T}$ cell to MDSC ratio in multiple lymphoid organs and within the TME. This reduction in effector $\mathrm{T}$ cells that occurs concurrently with an increase in immunosuppressive MDSCs may provide a robust inhibitory signal to prevent immune recognition of tumor antigens and immune-mediated tumor clearance.Thus, overweight and obesity-induced accumulation of MDSCs may contribute significantly to the exacerbation of tumor development. These data suggest that the maintenance of body weight over time, as observed in lean mice, has a protective effect on immune and tumor outcomes.

Obesity-induced alterations in myeloid markers were not limited to classic lymphoid organs or the TME. We observed increased gene expression of Gr1, Il6, and Il10 in the adipose of obese mice, suggesting an obesity-induced expansion in myeloid markers and cytokines that may promote the accumulation of immunosuppressive MDSCs [43]. An increase in the gene expression of Cd3, Arg1, and $T g f b$ was observed in adipose tissue of obese mice further demonstrating an abundance of immune cell markers and immune suppressive signaling pathways associated with myeloid cells [42]. The role of $\mathrm{Gr}-1^{+} \mathrm{CD} 11 \mathrm{~b}^{+}$cells within adipose tissue may have opposing effects in tumor-free vs. tumor-bearing hosts. Xia, et al. [63] report that $\mathrm{Gr}-1^{+} \mathrm{CD} 11 \mathrm{~b}^{+}$cells accumulate in the adipose of genetically obese (ob/ob) tumor-free animals in comparison to wild-type controls, and improve insulin sensitivity and reduce serum IL-6, suggesting that MDSCs may be negative regulators of obesity-induced inflammation in the absence of tumor. Our data demonstrate that in pancreatic tumor-bearing animals, increased adiposity results in the accumulation of myeloid-lineage and immunosuppressive factors in adipose tissue. Further studies are needed to determine the role of myeloid-lineage cells within the adipose tissue of tumor-bearing hosts.

Obesity is associated with alterations in the infiltration and accumulation of immune cells into adipose tissue that further contribute to chronic inflammation and dysregulated metabolism [64]. To separate the effects of obesity-induced inflammation from tumor-derived factors, which can stimulate MDSC expansion and accumulation, we examined the effect of increased adiposity on myeloid-lineage cells in tumor-free animals. Similar to a previous report demonstrating MDSC accumulation in the bone marrow, blood, spleen, adipose tissue, and liver of genetically obese (ob/ob), tumor-free animals [63], we observed increased $\mathrm{Gr}-1^{+} \mathrm{CD} 11 \mathrm{~b}^{+}$cells in immune organs from diet-induced overweight and obese mice in the absence of tumor. These data suggest that increased adiposity may be creating a proinflammatory and immunosuppressive environment prior to tumor development. Ma et al., demonstrate that MDSCs collected from patients with premalignant lesions were similar in subpopulation composition and immunosuppressive capacity to MDSCs collected from cancer patients, and that levels of MDSC in premalignancy correlate negatively with in vivo effector responses [65]. Thus, it may be that increasing adiposity in the absence of tumor contributes significantly to immune suppression via the accumulation of immunosuppressive MDSCs, which create an environment conducive to tumor initiation and/or growth. However, the full extent to which MDSCs and the inflammatory environment associated with increased adiposity contribute to cancer progression and/or response to therapy remains unclear.

\section{Conclusions}

In conclusion, we observed a linear relationship between increased adiposity, enhanced tumor growth, and decreased survival. These changes occurred concurrently with an expansion of immunosuppressive cells in lymphoid organs and within the TME, as well as increased expression of suppressive and inflammatory markers within the adipose tissue of tumor-bearing mice. Furthermore, increased adiposity expanded myeloid-lineage cells in the absence of tumor, demonstrating that obesity-induced alterations in myeloid populations can occur within secondary lymphoid organs. These results contribute to our understanding of the role of increasing adiposity on inflammatory and tumor-associated immunosuppressive factors. Understanding the detrimental effects of increased adiposity on the emergence of immunosuppressive cell types and identifying agents that block this expansion may reduce cancer progression and improve response rates to current and emerging therapies in patients diagnosed with numerous cancer types. 
Supplementary Materials: The following are available online at http://www.mdpi.com/2072-6643/11/12/3012/s1, Table S1: Diet Formulations; Table S2: List of antibodies for flow cytometry; Table S3: Effect of increased adiposity on splenic immune cell Distribution; Table S4: Effect of increased adiposity on TDLN immune cell distribution; Figure S1. Metabolic and inflammatory mediators in the plasma of tumor free and Panc.02 tumor-bearing mice. Plasma levels of (A, D) insulin (B, E) leptin and (C, F) IL-6 were measured in TF ( $n=5-7 /$ group) and Panc.02 tumor-bearing mice day at 60 day post-tumor implantation $(n=5-8 /$ group $)$ using the Milliplex MAP Multiplex Assay, respectively. Adiposity increased plasma insulin $\left(\mathrm{F}_{(2,12)}=6.71, p=0.011, \log\right.$ rank test for trend $\left.p=0.003\right)$, leptin $\left(\mathrm{F}_{(2,12)}=19.50, p<0.001, \log\right.$ rank test for trend $\left.p<0.001\right)$, and IL-6 $\left(\mathrm{F}_{(2,12)}=15.56, p<0.001, \log\right.$ rank test for trend $p<0.001)$ in tumor free mice $(\mathrm{A}-\mathrm{C})$. Adiposity increased plasma insulin $\left(\mathrm{F}_{(2,17)}=3.95, p=0.039, \log\right.$ rank test for trend $p=0.014)$, leptin $\left(\mathrm{F}_{(2,17)}=15.16, p<0.001\right.$, log rank test for trend $\left.p<0.001\right)$, and IL-6 $\left(\mathrm{F}_{(2,17)}=3.59\right.$, $p=0.048, \log$ rank test for trend $p=0.019)$ in tumor-bearing mice $(\mathrm{D}-\mathrm{F})$.

Author Contributions: W.J.T., S.D.C. and C.J.R. participated in the conception and design of the work. W.J.T., S.D.C., H.M. and C.J.R. performed experimental design and data acquisition and analysis. W.J.T., S.D.C. and C.J.R. participated in the interpretation of data, manuscript writing, and revision. All authors approved the final version for submission and publishing and agree to be accountable for all aspects of the work in ensuring that questions related to the accuracy or integrity of any part of the work are appropriately investigated and resolved.

Funding: This research was supported by a grant from the National Cancer Institute (R03CA166664), pilot funds through the Department of Nutritional Sciences and The College of Health and Human Development at Penn State University, and Broadhurst Career Development Funds. William J Turbitt was supported by a T32 Training Program (T32AI074551) in Animal Models of Inflammation while at Pennsylvania State University. William J Turbitt is currently funded by the NIH T32CA183926 grant; Research Training Program in Basic and Translational Oncology, The University of Alabama at Birmingham School of Medicine Department of Medicine, Division of Hematology and Oncology, Birmingham, AL, USA. Shawntawnee Collins was supported by Penn State's Clinical Translation Institute, The Sloan Foundation, and Graduate Research Funding provided through the Department of Nutritional Sciences at Penn State University.

Acknowledgments: We thank the Flow Cytometry Facility and the Genomics Core Facility in the Huck Institutes of Life Sciences at the Pennsylvania State University for the use of the core facility and technical support of this project.

Conflicts of Interest: The authors declare that the research was conducted in the absence of any commercial or financial relationships that could be construed as a potential conflict of interest.

\section{Abbreviations}

APC: antigen presenting cell; BMI, body mass index; DC, dendritic cell; IL, Interleukin; i.p., intraperitoneal, MDSC, myeloid-derived suppressor cell; MLR, mixed lymphocyte reaction; NK, natural killer; s.c., subcutaneous; TDLN, tumor-draining lymph nodes; TF, tumor-free.

\section{References}

1. Torre, L.A.; Siegel, R.; Ward, E.; Jemal, A. Global Cancer Incidence and Mortality Rates and Trends-An Update. Cancer Epidemiol. Biomark. Prev. 2016, 25, 16-27. [CrossRef] [PubMed]

2. Lauby-Secretan, B.; Scoccianti, C.; Loomis, D.; Grosse, Y.; Bianchini, F.; Straif, K.; International Agency for Research on Cancer Handbook Working Group. Body Fatness and Cancer-Viewpoint of the IARC Working Group. N. Engl. J. Med. 2016, 375, 794-798. [CrossRef] [PubMed]

3. Steele, C.B.; Thomas, C.C.; Henley, S.J.; Massetti, G.M.; Galuska, D.A.; Agurs-Collins, T.; Puckett, M.; Richardson, L.C. Vital signs: Trends in incidence of cancers associated with overweight and obesity-United States, 2005-2014. MMWR. Morb. Mortal. Wkly. Rep. 2017, 66, 1052. [CrossRef] [PubMed]

4. Majumder, K.; Gupta, A.; Arora, N.; Singh, P.P.; Singh, H. Premorbid Obesity and Mortality in Patients with Pancreatic Cancer: A Systematic Review and Meta-analysis. Clin. Gastroenterol. Hepatol. 2016, 14, 355-368. [CrossRef] [PubMed]

5. Chan, D.S.; Vieira, A.R.; Aune, D.; Bandera, E.V.; Greenwood, D.C.; McTiernan, A.; Rosenblatt, D.N.; Thune, I.; Vieira, R.; Norat, T. Body mass index and survival in women with breast cancer-systematic literature review and meta-analysis of 82 follow-up studies. Ann. Oncol. 2014, 25, 1901-1914. [CrossRef]

6. Turbitt, W.J.; Xu, Y.; Sosnoski, D.M.; Collins, S.D.; Meng, H.; Mastro, A.M.; Rogers, C.J. Physical Activity Plus Energy Restriction Prevents 4T1.2 Mammary Tumor Progression, MDSC Accumulation, and an Immunosuppressive Tumor Microenvironment. Cancer Prev. Res. (Phila) 2019, 12, 493-506. [CrossRef] 
7. Genkinger, J.M.; Kitahara, C.M.; Bernstein, L.; Berrington de Gonzalez, A.; Brotzman, M.; Elena, J.W.; Giles, G.G.; Hartge, P.; Singh, P.N.; Stolzenberg-Solomon, R.Z.; et al. Central adiposity, obesity during early adulthood, and pancreatic cancer mortality in a pooled analysis of cohort studies. Ann. Oncol. 2015, 26, 2257-2266. [CrossRef]

8. Esbenshade, A.J.; Simmons, J.H.; Koyama, T.; Koehler, E.; Whitlock, J.A.; Friedman, D.L. Body mass index and blood pressure changes over the course of treatment of pediatric acute lymphoblastic leukemia. Pediatr. Blood Cancer 2011, 56, 372-378. [CrossRef]

9. Withycombe, J.S.; Post-White, J.E.; Meza, J.L.; Hawks, R.G.; Smith, L.M.; Sacks, N.; Seibel, N.L. Weight patterns in children with higher risk ALL: A report from the Children's Oncology Group (COG) for CCG 1961. Pediatr. Blood Cancer 2009, 53, 1249-1254. [CrossRef]

10. Zhang, F.F.; Rodday, A.M.; Kelly, M.J.; Must, A.; MacPherson, C.; Roberts, S.B.; Saltzman, E.; Parsons, S.K. Predictors of being overweight or obese in survivors of pediatric acute lymphoblastic leukemia (ALL). Pediatr. Blood Cancer 2014, 61, 1263-1269. [CrossRef]

11. Curtis, R.E.; Freedman, D.M.; Ron, E.; Ries, L.A.G.; Hacker, D.G.; Edwards, B.K.; Tucker, M.A.; Fraumeni, J.F., Jr. (Eds.) New Malignancies Among Cancer Survivors: SEER Cancer Registries, 1973-2000; NIH Publ. No. 05-5302; National Cancer Institute: Bethesda, MD, USA, 2006.

12. Meadows, A.T.; Friedman, D.L.; Neglia, J.P.; Mertens, A.C.; Donaldson, S.S.; Stovall, M.; Hammond, S.; Yasui, Y.; Inskip, P.D. Second neoplasms in survivors of childhood cancer: Findings from the Childhood Cancer Survivor Study cohort. J. Clin. Oncol. 2009, 27, 2356-2362. [CrossRef] [PubMed]

13. Moke, D.J.; Hamilton, A.S.; Chehab, L.; Deapen, D.; Freyer, D.R. Obesity and Risk for Second Malignant Neoplasms in Childhood Cancer Survivors: A Case-Control Study Utilizing the California Cancer Registry. Cancer Epidemiol. Biomark. Prev. 2019, 28, 1612-1620. [CrossRef] [PubMed]

14. Cozzo, A.J.; Fuller, A.M.; Makowski, L. Contribution of Adipose Tissue to Development of Cancer. Compr. Physiol. 2017, 8, 237-282. [PubMed]

15. Donohoe, C.L.; Lysaght, J.; O'Sullivan, J.N.; Reynolds, J.V. Emerging Concepts Linking Obesity with the Hallmarks of Cancer. Trends Endocrinol. Metab. 2017, 28, 46-62. [CrossRef] [PubMed]

16. Dyck, L.; Lynch, L. Cancer, obesity and immunometabolism-Connecting the dots. Cancer Lett. 2018, 417, 11-20. [CrossRef]

17. Bantug, G.R.; Galluzzi, L.; Kroemer, G.; Hess, C. The spectrum of T cell metabolism in health and disease. Nat. Rev. Immunol. 2017, 18, 19. [CrossRef]

18. Michelet, X.; Dyck, L.; Hogan, A.; Loftus, R.M.; Duquette, D.; Wei, K.; Beyaz, S.; Tavakkoli, A.; Foley, C.; Donnelly, R.; et al. Metabolic reprogramming of natural killer cells in obesity limits antitumor responses. Nat. Immunol. 2018, 19, 1330-1340. [CrossRef]

19. Ostrand-Rosenberg, S. Myeloid derived-suppressor cells: Their role in cancer and obesity. Curr. Opin. Immunol. 2018, 51, 68-75. [CrossRef]

20. Sica, A.; Massarotti, M. Myeloid suppressor cells in cancer and autoimmunity. J. Autoimmun. 2017, 85, 117-125. [CrossRef]

21. Kumar, V.; Patel, S.; Tcyganov, E.; Gabrilovich, D.I. The Nature of Myeloid-Derived Suppressor Cells in the Tumor Microenvironment. Trends Immunol. 2016, 37, 208-220. [CrossRef]

22. van der Poll, T. Myeloid-derived Suppressor Cells in Sepsis. Am. J. Respir. Crit. Care Med. 2017, 196, $256-258$. [CrossRef] [PubMed]

23. Gabrilovich, D.I.; Nagaraj, S. Myeloid-derived suppressor cells as regulators of the immune system. Nat. Rev. Immunol. 2009, 9, 162-174. [CrossRef]

24. Diaz-Montero, C.M.; Salem, M.L.; Nishimura, M.I.; Garrett-Mayer, E.; Cole, D.J.; Montero, A.J. Increased circulating myeloid-derived suppressor cells correlate with clinical cancer stage, metastatic tumor burden, and doxorubicin-cyclophosphamide chemotherapy. Cancer Immunol. Immunother. 2009, 58, 49-59. [CrossRef] [PubMed]

25. Gabitass, R.F.; Annels, N.E.; Stocken, D.D.; Pandha, H.A.; Middleton, G.W. Elevated myeloid-derived suppressor cells in pancreatic, esophageal and gastric cancer are an independent prognostic factor and are associated with significant elevation of the Th2 cytokine interleukin-13. Cancer Immunol. Immunother. 2011, 60, 1419-1430. [CrossRef] [PubMed] 
26. Nagaraj, S.; Youn, J.-I.; Gabrilovich, D.I. Reciprocal relationship between myeloid-derived suppressor cells and T cells. J. Immunol. 2013, 191, 17-23. [CrossRef]

27. American Cancer Society. Cancer Facts \& Figures; ACS: Atlanta, GA, USA, 2018.

28. Fukunaga, A.; Miyamoto, M.; Cho, Y.; Murakami, S.; Kawarada, Y.; Oshikiri, T.; Kato, K.; Kurokawa, T.; Suzuoki, M.; Nakakubo, Y.; et al. CD8+ tumor-infiltrating lymphocytes together with CD4+ tumor-infiltrating lymphocytes and dendritic cells improve the prognosis of patients with pancreatic adenocarcinoma. Pancreas 2004, 28, e26-e31. [CrossRef] [PubMed]

29. Stromnes, I.M.; Hulbert, A.; Pierce, R.H.; Greenberg, P.D.; Hingorani, S.R. T-cell Localization, Activation, and Clonal Expansion in Human Pancreatic Ductal Adenocarcinoma. Cancer Immunol. Res. 2017, 5, 978-991. [CrossRef] [PubMed]

30. Li, J.; Byrne, K.T.; Yan, F.; Yamazoe, T.; Chen, Z.; Baslan, T.; Richman, L.P.; Lin, J.H.; Sun, Y.H.; Rech, A.J.; et al. Tumor Cell-Intrinsic Factors Underlie Heterogeneity of Immune Cell Infiltration and Response to Immunotherapy. Immunity 2018, 49, 178-193. [CrossRef]

31. Mace, T.A.; Ameen, Z.; Collins, A.; Wojcik, S.; Mair, M.; Young, G.S.; Fuchs, J.R.; Eubank, T.D.; Frankel, W.L.; Bekaii-Saab, T.; et al. Pancreatic cancer-associated stellate cells promote differentiation of myeloid-derived suppressor cells in a STAT3-dependent manner. Cancer Res. 2013, 73, 3007-3018. [CrossRef]

32. Pergamo, M.; Miller, G. Myeloid-derived suppressor cells and their role in pancreatic cancer. Cancer Gene Ther. 2017, 24, 100-105. [CrossRef]

33. Incio, J.; Liu, H.; Suboj, P.; Chin, S.M.; Chen, I.X.; Pinter, M.; Ng, M.R.; Nia, H.T.; Grahovac, J.; Kao, S.; et al. Obesity-Induced Inflammation and Desmoplasia Promote Pancreatic Cancer Progression and Resistance to Chemotherapy. Cancer Discov. 2016, 6, 852-869. [CrossRef] [PubMed]

34. Incio, J.; Tam, J.; Rahbari, N.N.; Suboj, P.; McManus, D.T.; Chin, S.M.; Vardam, T.D.; Batista, A.; Babykutty, S.; Jung, K.; et al. PlGF/VEGFR-1 Signaling Promotes Macrophage Polarization and Accelerated Tumor Progression in Obesity. Clin. Cancer Res. 2016, 22, 2993-3004. [CrossRef] [PubMed]

35. Lashinger, L.M.; Harrison, L.M.; Rasmussen, A.J.; Logsdon, C.D.; Fischer, S.M.; McArthur, M.J.; Hursting, S.D. Dietary energy balance modulation of Kras- and Ink4a/Arf+/-driven pancreatic cancer: The role of insulin-like growth factor-I. Cancer Prev. Res. (Phila) 2013, 6, 1046-1055. [CrossRef] [PubMed]

36. Hance, K.W.; Rogers, C.J.; Zaharoff, D.A.; Canter, D.; Schlom, J.; Greiner, J.W. The antitumor and immunoadjuvant effects of IFN-alpha in combination with recombinant poxvirus vaccines. Clin. Cancer Res. 2009, 15, 2387-2396. [CrossRef] [PubMed]

37. Sivinski, C.L.; Kohlgraf, K.G.; VanLith, M.L.; Morikane, K.; Tempero, R.M.; Hollingsworth, M.A. Molecular requirements for CD8-mediated rejection of a MUC1-expressing pancreatic carcinoma: Implications for tumor vaccines. Cancer Immunol. Immunother. 2002, 51, 327-340. [CrossRef]

38. Rogers, C.J.; Berrigan, D.; Zaharoff, D.A.; Hance, K.W.; Patel, A.C.; Perkins, S.N.; Schlom, J.; Greiner, J.W.; Hursting, S.D. Energy restriction and exercise differentially enhance components of systemic and mucosal immunity in mice. J. Nutr. 2008, 138, 115-122. [CrossRef]

39. Rogers, C.J.; Zaharoff, D.A.; Hance, K.W.; Perkins, S.N.; Hursting, S.D.; Schlom, J.; Greiner, J.W. Exercise enhances vaccine-induced antigen-specific $\mathrm{T}$ cell responses. Vaccine 2008, 26, 5407-5415. [CrossRef]

40. Turbitt, W.J.; Black, A.J.; Collins, S.D.; Meng, H.; Xu, H.; Washington, S.; Aliaga, C.; El-Bayoumy, K.; Manni, A.; Rogers, C.J. Fish Oil Enhances T Cell Function and Tumor Infiltration and Is Correlated With a Cancer Prevention Effect in HER-2/neu But Not PyMT Transgenic Mice. Nutr. Cancer 2015, 67, 965-975. [CrossRef]

41. Livak, K.J.; Schmittgen, T.D. Analysis of relative gene expression data using real-time quantitative PCR and the 2(-Delta Delta C.(T)) Method. Methods 2001, 25, 402-408. [CrossRef]

42. Chen, J.; Ye, Y.; Liu, P.; Yu, W.; Wei, F.; Li, H.; Yu, J. Suppression of T cells by myeloid-derived suppressor cells in cancer. Hum. Immunol. 2017, 78, 113-119. [CrossRef]

43. Steggerda, S.M.; Bennett, M.K.; Chen, J.; Emberley, E.; Huang, T.; Janes, J.R.; Li, W.; MacKinnon, A.L.; Makkouk, A.; Marguier, G.; et al. Inhibition of arginase by CB-1158 blocks myeloid cell-mediated immune suppression in the tumor microenvironment. J. Immunother. Cancer 2017, 5, 101. [CrossRef] [PubMed]

44. World Health Organization. Overweight/Obesity Fact Sheet; World Health Organization: Geneva, Switzerland, 2018. 
45. Hales, C.M.; Fryar, C.D.; Carroll, M.D.; Freedman, D.S.; Ogden, C.L. Trends in Obesity and Severe Obesity Prevalence in US Youth and Adults by Sex and Age, 2007-2008 to 2015-2016. Jama 2018, 319, 1723-1725. [CrossRef] [PubMed]

46. Quail, D.F.; Dannenberg, A.J. The obese adipose tissue microenvironment in cancer development and progression. Nat. Rev. Endocrinol. 2018, 1. [CrossRef] [PubMed]

47. Greenberg, A.S.; Obin, M.S. Obesity and the role of adipose tissue in inflammation and metabolism. Am. J. Clin. Nutr. 2006, 83, 461S-465S. [CrossRef] [PubMed]

48. Booth, A.; Magnuson, A.; Fouts, J.; Foster, M. Adipose tissue, obesity and adipokines: Role in cancer promotion. Horm. Mol. Biol. Clin. Investig. 2015, 21, 57-74. [CrossRef]

49. Stolzenberg-Solomon, R.Z.; Newton, C.C.; Silverman, D.T.; Pollak, M.; Nogueira, L.M.; Weinstein, S.J.; Albanes, D.; Männistö, S.; Jacobs, E.J. Circulating leptin and risk of pancreatic cancer: A pooled analysis from 3 cohorts. Am. J. Epidemiol. 2015, 182, 187-197. [CrossRef]

50. Mendonsa, A.M.; Chalfant, M.C.; Gorden, L.D.; VanSaun, M.N. OModulation of the leptin receptor mediates tumor growth and migration of pancreatic cancer cells. PLoS ONE 2015, 10, e0126686. [CrossRef]

51. Zyromski, N.J.; Mathur, A.; Pitt, H.A.; Wade, T.E.; Wang, S.; Nakshatri, P.; Swartz-Basile, D.A.; Nakshatri, H. Obesity potentiates the growth and dissemination of pancreatic cancer. Surgery 2009, 146, 258-263. [CrossRef]

52. White, P.B.; Ziegler, K.M.; Swartz-Basile, D.A.; Wang, S.S.; Lillemoe, K.D.; Pitt, H.A.; Zyromski, N.J. Obesity, But Not. High.-Fat Diet., Promotes Murine Pancreatic Cancer Growth. J. Gastrointest. Surg. 2012, 16, 1680-1685. [CrossRef]

53. McWilliams, R.R.; Matsumoto, M.E.; Burch, P.A.; Kim, G.P.; Halfdanarson, T.R.; De Andrade, M.; Reid-Lombardo, K.; Bamlet, W.R. Obesity adversely affects survival in pancreatic cancer patients. Cancer 2010, 116, 5054-5062. [CrossRef]

54. Arslan, A.A.; Helzlsouer, K.J.; Kooperberg, C.; Shu, X.O.; Steplowski, E.; Bueno-de-Mesquita, H.B.; Fuchs, C.S.; Gross, M.D.; Jacobs, E.J.; Lacroix, A.Z.; et al. Anthropometric measures, body mass index, and pancreatic cancer: A pooled analysis from the Pancreatic Cancer Cohort Consortium (PanScan). Arch. Intern. Med. 2010, 170, 791-802. [CrossRef] [PubMed]

55. Aguilar, E.G.; Murphy, W.J. Obesity induced T cell dysfunction and implications for cancer immunotherapy. Curr. Opin. Immunol. 2018, 51, 181-186. [CrossRef] [PubMed]

56. Veglia, F.; Perego, M.; Gabrilovich, D. Myeloid-derived suppressor cells coming of age. Nat. Immunol. 2018, 19, 108-119. [CrossRef] [PubMed]

57. Ostrand-Rosenberg, S.; Sinha, P. Myeloid-derived suppressor cells: Linking inflammation and cancer. J. Immunol. 2009, 182, 4499-4506. [CrossRef] [PubMed]

58. Porembka, M.R.; Mitchem, J.B.; Belt, B.A.; Hsieh, C.S.; Lee, H.M.; Herndon, J.; Gillanders, W.E.; Linehan, D.C.; Goedegebuure, P. Pancreatic adenocarcinoma induces bone marrow mobilization of myeloid-derived suppressor cells which promote primary tumor growth. Cancer Immunol. Immunother. 2012, 61, 1373-1385. [CrossRef] [PubMed]

59. Hale, M.; Itani, F.; Buchta, C.M.; Wald, G.; Bing, M.; Norian, L.A. Obesity triggers enhanced MDSC accumulation in murine renal tumors via elevated local production of CCL2. PLoS ONE 2015, 10, e0118784. [CrossRef]

60. Khaled, Y.S.; Ammori, B.J.; Elkord, E. Increased levels of granulocytic myeloid-derived suppressor cells in peripheral blood and tumour tissue of pancreatic cancer patients. J. Immunol. Res. 2014, 2014, 879897. [CrossRef]

61. Markowitz, J.; Brooks, T.R.; Duggan, M.C.; Paul, B.K.; Pan, X.; Wei, L.; Abrams, Z.; Luedke, E.; Lesinski, G.B.; Mundy-Bosse, B.; et al. Patients with pancreatic adenocarcinoma exhibit elevated levels of myeloid-derived suppressor cells upon progression of disease. Cancer Immunol. Immunother. 2015, 64, 149-159. [CrossRef]

62. Basso, D.; Fogar, P.; Plebani, M. The S100A8/A9 complex reduces CTLA4 expression by immature myeloid cells: Implications for pancreatic cancer-driven immunosuppression. Oncoimmunology 2013, 2, e24441. [CrossRef]

63. Xia, S.; Sha, H.; Yang, L.; Ji, Y.; Ostrand-Rosenberg, S.; Qi, L. Gr-1+ CD11b+ myeloid-derived suppressor cells suppress inflammation and promote insulin sensitivity in obesity. J. Biol. Chem. 2011, 286, 23591-23599. [CrossRef] 
64. Russo, L.; Lumeng, C.N. Properties and functions of adipose tissue macrophages in obesity. Immunology 2018, 155, 407-417. [CrossRef] [PubMed]

65. Ma, P.; Sha, H.; Yang, L.; Ji, Y.; Ostrand-Rosenberg, S.; Qi, L. Circulating Myeloid Derived Suppressor Cells (MDSC) That Accumulate in Premalignancy Share Phenotypic and Functional Characteristics with MDSC in Cancer. Front. Immunol. 2019, 10, 1401. [CrossRef] [PubMed] 